\title{
Coletivos de música eletrônica em São Paulo: usos da cidade, culturas juvenis e sentidos políticos
}

\section{Simone Luci Pereira e Oziel Gheirart}

\section{Resumo}

Analisamos uma recente cena da música eletrônica de pista, que vem ocorrendo nas ruas das áreas centrais de São Paulo, articulada às discussões e às ações ocorridas na cidade sobre seus usos e sobre cidadania urbana. Evidencia-se a centralidade da música e sua dimensão comunicacional e política: dança, corpo e performatividade das identidades aliadas à construção de modos de estar juntos e ocupar a cidade. A metodologia centra-se na etnografia, e enfocamos as ações de três coletivos ligados a esta cena em São Paulo. Como resultados apresentamos alguns desdobramentos e sentidos políticos aí engendrados: formas colaborativas e autogestionárias; maneiras de ocupar os espaços públicos e reivindicar o direito à cidade; dimensões lúdicas e afetuais aí presentes.

\section{Palavras-Chave}

Música eletrônica. Cidade. Culturas juvenis.

\section{Simone Luci Pereira}

Doutora em Ciências Sociais - Antropologia (2004) pela Pontifícia Universidade Católica de São Paulo (PUCSP). Professora titular do Programa de Pós-Graduação em Comunicação e Cultura Midiática da Universidade Paulista - UNIP, São Paulo, São Paulo, Brasil.

E-mail: simonelp@uol.com.br

https://orcid.org/0000-0002-7412-2129

\section{Oziel Gheirart}

Doutor em Ciências Sociais pela Pontifícia Universidade Católica de São Paulo (PUCSP). Músico e produtor, idealizador do projeto multi artes Baladeur. Integrante do GP Juvenália (ESPM) e do GP Musimid (UNIP). E-mail: gheirart@yahoo.com https://orcid.org/0000-0002-6035-9248

\section{Introdução}

Refletir sobre espaços urbanos públicos na cidade de São Paulo mostra-se como uma tarefa complexa ${ }^{1}$. Essa complexidade advém de uma memória histórica e social da qual somos herdeiros, que construiu e ainda constrói a cidade por uma certa lógica que tem origem nos bandeirantes e é ligada às difusas noções de "locomotiva do país": local de passagem, edificada em torno dos espaços das propriedades privadas, lugar de trabalho, não possuidora de uma vida pública - sobretudo, se compararmos ao Rio de Janeiro, por exemplo, edificado social, culturalmente e nos imaginários na vida das ruas.

Claro que ainda é forte, entre muitos dos paulistanos e nas práticas do poder estatal, uma política que pouco contempla (com raras exceções) o estímulo da vida e dos lazeres nos espaços públicos². Entretanto, temos percebido - como pesquisadores e errantes pela cidade - aspectos, indícios e pistas de que há que se perguntar mais detidamente sobre essa suposta vocação paulistana para os espaços fechados, 
ou ao menos desconstruir os seus sentidos unívocos e totalizantes.

Nos últimos anos, os autores deste artigo têm, por diferentes caminhos, vivido estas questões que envolvem as práticas musicais-midiáticas, as culturas urbanas e juvenis e os usos da cidade por coletivos de jovens, e refletido sobre isso. Esses jovens buscam encontrar meios criativos para inventarem formas de estar juntos, produzir, fazer e divulgar músicas, usar e se apropriar da cidade, re-territorializar lugares e outorgar sentidos políticos a essas experiências urbanas. É uma criatividade que se mostra não só nas expressões musicais e performativas (autoria, combinação de gêneros, fusões, instalações, etc.), como também nas formas de gerir espaços de música, festas, eventos, associações e formas de cooperação (PEREIRA, 2017). Mais ainda, nos últimos anos, percebemos uma ocupação cada vez maior dos espaços públicos tradicionais, como ruas, praças, túneis subterrâneos, em ações protagonizadas pelos próprios coletivos e, tantas vezes, desafiando institucionalidades como prefeitura, CET (Companhia de Engenharia de Tráfego), polícia e, mesmo, as datas dos eventos oficiais de usos da rua, como a Virada

Cultural ou o evento SP na Rua (ainda que também participem deste, do qual falaremos mais a frente).

0 aprofundamento do debate sobre os usos dos espaços públicos e da vocação das cidades também vem sendo atestado com o Carnaval de Rua em São Paulo e o crescimento, a proliferação e a adesão de grande parte da população aos blocos de rua nos últimos cinco anos aproximadamente. Lembramos que há o poder público dificultando, impondo limites de horário, regras quase inexequíveis, buscando edificar uma espécie de "circuito de Carnaval", concentrando todos os blocos na Avenida 23 de Maio, aos moldes do Carnaval privatizado de Salvador, e para que não atrapalhe o trânsito. Apesar disso, vem ocorrendo uma forte mudança nos debates e nas práticas que envolvem o uso das ruas - veja-se a Avenida Paulista aberta para pedestres aos domingos. Isso gera ainda muitas reclamações dos que entendem a cidade como local de carros, mas há cada vez maior adesão, apoio e uso por parte dos sujeitos urbanos, que querem ocupar as ruas numa cidade cujo discurso oficial, cultural e

Uma versão deste artigo foi apresentada no Grupo de Trabalho Comunicação e Estudos de Som e Música do XXVII Encontro Anual da Compós, Pontifícia Universidade Católica de Minas Gerais, Belo Horizonte - MG, 05 a 08 de junho de 2018.

A noção de espaço público oriunda da Modernidade republicana precisa ser recolocada, como sugere Delgado, (2007). A noção de que esta seria o oposto do espaço da vida privada, como a ágora de decisões coletivas, espaço da igualdade sem assimetrias e com a participação de iguais, é uma quimera e uma ideologia. Neste sentido, há que se pensar na noção de espaços semipúblicos (rompendo com a dicotomia público/privado), como aqueles onde se produzem relações em público, vínculos que se estabelecem entre pessoas que não se conhecem ou se conhecem de vista e vão negociar sentidos, englobando diferentes graus de acesso, disponibilidade e promoção de encontros (REIA, 2018). Nesta concepção, o espaço público não pode ser pensado como um dado em si, mas é fruto das práticas que ocorrem nele, fruto dos usos que recebe. 
historicamente construído ainda se refere a um lugar sem lazer, beleza e espaços públicos.

Neste contexto, algumas festas de música eletrônica feitas nas ruas têm nos chamado a atenção: seja em ruas mais vazias nos finais de semana no bairro do Bom Retiro, seja em ruas, túneis e praças de áreas mais centrais da cidade. Essas festas se inserem num movimento mais amplo de festas independentes e underground, de música eletrônica de variadas vertentes e estilos, que vem ocorrendo em São Paulo. Acontecem mensalmente, bimestralmente ou de forma esporádica e de maneira mais artesanal, colaborativa, fora de casas noturnas ou bares. Algumas dessas festas são: Mamba Negra, Femine HiFi, Tantsa, ODD, Vampire Haus, Capslock, Festa Autônoma Temporária, entre outras. Elas acontecem em ruas e praças ou, ainda, em imóveis abandonados; os coletivos que as organizam têm que buscar autorizações e alvarás para cada um dos eventos - tarefa que se tornou mais difícil e burocrática na atual gestão da Prefeitura de São Paulo, a partir de 2017, em que as leis para o uso do espaço público tornaram-se mais rígidas e proibitivas, o que faz com que esses grupos tenham que inventar formas de atuação e negociação.
Neste artigo abordaremos as práticas musicais-midiáticas de três coletivos ligados à música eletrônica de pista ${ }^{3}$ em São Paulo: Síntese Coletiva, Mamba Negra e AutônomaAtemporária. A escolha por esse recorte justifica-se por apresentarem elementos em comum, os quais nos levam ao nosso objetivo neste texto, que é o de compreender 1.) as festas produzidas, analisadas a partir de pesquisa de base etnográfica, entrevistas com produtores e frequentadores, tendo em vista: a.) a sonoridade ali presente e a produção musical'; e b.) as atividades de produção das festas, sua economia política (produção, divulgação, organização). Ao mesmo tempo, também queremos compreender 2.) as atividades "extrafesta" realizadas por esses coletivos, como cursos, oficinas, encontros, festivais etc. Todos esses eventos vêm evidenciando a centralidade da música e sua dimensão comunicacional, explicitadas nestas festas, uma vez que reúnem pessoas para dançar, performatizar e visibilizar identidades, construir vinculações, formas de estar juntos e ocupar a cidade.

Começamos 0 artigo com um breve histórico da cena eletrônica em São Paulo, cujo auge deu-se nos anos 1990/2000 nos clubes, e uma movimentação dessa cena para as festas de rua. Em seguida,

Segundo alguns atores entrevistados, o termo "música eletrônica de pista" abrange o house, o techno e suas vertentes, bem como propostas mais contemporâneas de música eletrônica. Estes têm em comum a pista de dança como centralidade e envolvem variadas práticas musicais, como DJs, live performers, produtores, técnicos de som, artistas visuais, público.

Faz parte dos objetivos desta pesquisa analisar também as visualidades e estéticas presentes nessas festas, na forma de corporalidades, indumentárias, flyers, projeções, entre outros aspectos. Entretanto, esse será assunto para um outro artigo. 
analisamos as atividades dos coletivos elegidos aqui, articulados a uma reflexão que tem como marcos teóricos as questões sobre performance/ performatividade, afetos, corporalidades e cidades.

Acionamos debates advindos dos estudos urbanos, da geografia cultural e da antropologia urbana, que têm nos ajudado a refletir sobre as questões do espaço (simbólico, imaginado, praticado, disputado) e da vida urbana como fruto das interrelações, dos fluxos, das errâncias, do inesperado, do imprevisível e das dissidências articuladas às identidades, formas de resistência e direito à cidade. Este caminho de reflexão é o que nos auxilia a compreender as relações que a música (em seus elementos afetuais e sensíveis) estabelece com os espaços e, neste caso, com os espaços públicos na cidade de São Paulo, alterando rotas pré-definidas de reflexão que muitas vezes deixam de perceber aspectos menos evidentes presentes nas culturas urbanas e juvenis. Aqui procuramos realçar esse emaranhando de redes tantas vezes invisíveis na cidade e a visibilidade/audibilidade dessas outras formas de viver o urbano.

\section{(Des)Caminhos da cena eletrônica}

Buscamos compreender a combinação de alguns elos e ecos particulares do percurso da música eletrônica alternativa em São Paulo (MARKE, 2017; CHIAVERINI, 2008). Iniciamos a apresentação deste cenário destacando 0 desenvolvimento da cibercultura como "forma sociocultural que emerge da relação simbiótica entre a sociedade, a cultura e as novas tecnologias de base microeletrônica" (LEMOS, 2003, p. 1), surgidas ainda na década de 1970, que desencadearam, dentre muitas coisas, o fenômeno da música eletrônica dançante na década de 1980. Essa música, que ainda entrava no país pelas importadoras, por pesquisadores e por colecionadores, era trabalhada basicamente pelas casas noturnas. Assim se abastecia uma nascente cena da música eletrônica, marcada naquele momento por características vinculadas a elementos subculturais e underground $^{5}$. Como estilos mais relevantes dentro desse contexto ressaltamos o synthpop ou tecnopop - o qual, dando continuidade à new wave, trouxe a junção da música eletrônica com o pop - e a eletronic body music, que resultou numa combinação dessa música de sintetizador com 0 industrial, originário do final da década de 1970.

No Brasil, uma cena concentrou-se nos eixos Sudeste (São Paulo, Rio de Janeiro e Belo Horizonte) e Sul (Porto Alegre e Curitiba).

Não faremos aqui uma discussão mais detalhada sobre a noção de subculturas, seus desdobramentos e críticas. Para isso, ver Amaral (2005) e Freire Filho (2005), para citar apenas alguns trabalhos. Apenas sinalizamos que essa noção tem suas bases nos Estudos Culturais nos anos 1970, em pesquisas que enfocavam juventudes urbanas em suas formas contrahegemônicas de resistência aos modelos culturais e sociais dominantes. Já a noção de pós-subcultura desloca a centralidade da resistência para aquilo que é ligado ao capital simbólico subcultural, no dizer de Thornton (1996). Utilizamos aqui subcultura e underground como noções dinâmicas e relacionais que identificam atitudes, comportamentos e expressões culturais que se querem fora dos modismos e do mainstream comercial, mas com os quais de alguma forma negociam sentidos. 
0 repertório eletrônico foi se popularizando cada vez mais com o passar do tempo, impulsionado pela crescente facilidade de acesso às tecnologias (SÁ, 2003; WOODSIDE; JIMENEZ, 2012). Porém, o grande boom aconteceu no início dos anos 1990, com o surgimento da dance music - que bebeu do funk e da soul music dos anos 1970. 0 estilo foi chamado de "poperô" pelos brasileiros por conta da música Pump up the jam, da banda belga Technotronic, cuja base era uma batida 4/4 de computador com 120 a 135 batidas por minuto.

Aliada ao avanço tecnológico, a música eletrônica disseminou-se em diversos estilos e tornou-se um produto midiático em escala universal. Em 1990, surge a primeira revista brasileira de música eletrônica, a DJ Sound, e com isso uma cena de Djs, bandas, clubes e estilos de vida foi se constituindo. Como pontua Amaral (2008, p. 40), "com tantas mudanças e amplificação de acesso à cultura digital nos últimos anos, 0 papel das subculturas em relação às tecnologias digitais também se alterou". Em São Paulo, as casas alternativas que mantinham estilos não comerciais, ainda na metade da década de 1990 foram substituindo os estilos musicais e as festas por modelos mais comerciais. Isso deu visibilidade para essa cena, fazendo com que surgissem outras casas, bandas e selos nacionais.
Convém articular a esse contexto uma certa decadência do projeto social e econômico capitalista ocidental nas últimas décadas aliado a uma busca de grupos juvenis urbanos por territórios de liberdades individuais e coletivas, que escapassem aos controles sociais. Assim, um movimento que iniciou na Europa, valendo-se da potência da música eletrônica, impulsionou 0 surgimento das raves - festas com mais de doze horas de duração, longe dos espaços urbanos, com interação entre Djs, artistas e público, além do diferencial de apresentar um repertório que não figurava nas casas noturnas, tais como techno, trance, drum and bass etc.

Os clubes tentaram se reinventar trazendo os after hours ${ }^{6}$ e, pouco antes dos anos 2000, imperaram como palco da música eletrônica, proliferando uma gama de atrações e trazendo artistas internacionais e de vanguarda.

Apareceram até mesmo festivais com atmosferas das raves, patrocinados por marcas de cigarros e de bebidas. Assim, pouco a pouco, as casas foram se alinhando às lógicas do poder econômico do capitalismo - o que Lipovetsky (2007) classifica como triunfal ${ }^{7}$, estabelecendo uma cultura VIP e fashionista. Por dentro, refletia o funcionamento da sociedade do capital de controle: proibição de drogas, de fumo, além da cobrança de ingressos

Festas que ocorrem após a programação "normal” das casas indo, às vezes, até o período da tarde.

Lipovestky chama de capitalismo da terceira fase. Desde fins dos anos 1970, iniciou-se uma relação emocional dos indivíduos com as mercadorias, provocando mudanças e instituindo a individualização nas sociedades, o que afetou diretamente as subjetividades coletivas. 
ou exigência de consumo mínimo, o falso crédito das comandas etc. As características mais criativas e inventivas no âmbito musical e comportamental foram cedendo espaço para as lógicas economicistas trazidas pela indústria da música.

No decorrer da década de 2000, a cena foi mudando e pulverizando-se. Contraditoriamente, a tecnologia desenvolvia-se propiciando uma música com mais melodia, mais bem arranjada, com cada vez maior qualidade centrada em torno do techno, do house e suas vertentes. Foi quando, em 2010, apareceram novas festas itinerantes que buscavam se apropriar dos territórios da cidade e ressignificar o sentido do festejar. Destacamos a Voodoohop ${ }^{8}$ e a Selvagem ${ }^{9}$ como precursoras desse movimento.

Nesse fluxo, a partir de 2013 vem se formando uma nova cena independente da música eletrônica em São Paulo. Apesar de ter sido articulada dentro desse cenário dos clubes por pessoas motivadas por viagens e vivências internacionais, esse movimento atual é formado por jovens que não vieram dos clubes. A sonoridade não é propriamente nova, e em comum há o desejo de buscar lugares onde se possam exercer liberdades individuais e coletivas, em que sentidos políticos de ocupação do espaço público se coadunem aos aspectos ligados aos usos do corpo e sua estetização igualmente com conotação política e como lócus de resistências articuladas em torno da dança e da performatividade (TAYLOR, 2012).

Esta nova cena trazia como características: 1) a centralidade da música - pista, produção, circulação, conexão, experiência sensória; e as práticas musicais - DJs, músicos, produtores, live-performers, artistas visuais, técnicos de som, promoters; 2) as tecnologias de informação usadas na estrutura na produção, circulação, divulgação; 3) a recuperação de uma atitude underground expressa nos comportamentos, na estetização e nos engajamentos; 4) os desdobramentos de ações políticas e artísticas concretas.

Frente à crise econômica mundial e à decadência social e urbanística de grandes centros urbanos, a ocupação das cidades transformou-se numa

Segundo o site do grupo, Voodoohop é um coletivo de arte estrangeira nascido de uma série de festas subterrâneas. Em 6 anos de eventos colaborativos, reuniu uma miríade de artistas de diferentes áreas - como DJs, artistas ao vivo, dançarinos e artistas visuais. Juntos criaram um cabaré tropical multissensorial, misturando visuais coloridos e exuberantes, combinados com elementos do patrimônio tradicional brasileiro e desempenho ritual. Na natureza nômade, o coletivo transformou espaços que vão desde edifícios abandonados até refúgios naturais, sempre experimentando diferentes mídias e formatos. Disponível em: <https://voodoohop.com/> Acesso em: Jan. de 2018.

Selvagem é o nome da dupla formada pelos DJs Millos Kaiser e Trepanado, bem como das festas que eles fazem em São Paulo e Rio de Janeiro. Como dizem, "acreditam no pensamento livre associativo quando se trata de música, canalizando-o com uma abordagem anárquica, misturando disco, house, rock, techno, funk e alma de todas as eras e lugares”. Disponível em: $<$ facebook.com/selvagem> Acesso em: Jan. de 2018. 
expressão de cidadania na atualidade e uma pauta urgente. Como sugere Harvey (2014), a luta de resistência aos ditames do capital financeiro deve ser global, pois esta é a escala na qual o processo de urbanização opera atualmente, e é em torno dele que as crises repetidamente irrompem local e globalmente. Neste sentido, 0 direito à cidade tem se tornado um lema operacional e um ideal político, como já havia preconizado Henri Lefebvre nos anos 1960/70 (LEFEBVRE, 2001).

Em São Paulo, por articulação e atuação de grupos ligados à cultura independente, foi criado, em 2007, o Mês da Cultura Independente - MCI, pela Prefeitura, destinado a promover estilos, coletivos, gêneros musicais fora do mainstream com ações em pontos diferentes da cidade. Esse projeto manteve-se pelas gestões de José Serra e Gilberto Kassab até 2012, e foi ampliada na gestão de Fernando Haddad (2013-2016). As festas de música eletrônica independente cresceram e se proliferaram, e os embates com o poder público e outras institucionalidades não tardaram em aparecer. Quase sempre organizadas por pequenos grupos que usavam apenas as redes sociais para divulgação, as festas que, a princípio, reuniam uma média de trezentas pessoas, passaram a ter público superior a mil pessoas, algo que exigiu um outro modo de operação. Algumas dessas festas, dispondo de poderosos sistemas de som e de convidados, dependem de substanciais investimentos que começaram a não se bancarem, pois a proliferação dos eventos nesse formato dispersou o público e comprometeu o próprio campo que havia se aberto.

Ao mesmo tempo, estas festas começaram a lidar diretamente com demandas fulcrais da sociedade, chamando a atenção para questões sociais com apoio às causas políticas e de minorias, revitalizando o centro da cidade, trazendo as periferias e os moradores de rua. Isso provocou um grande alvoroço no espaço público, e, por conta de uma economia própria (ingressos, bar, serviços, táxi, acessórios etc.), roubou uma fatia do poder econômico hegemônico.

Com a mudança de gestão na Prefeitura em 2017, novas medidas foram implementadas e, de uma forma geral, as políticas das gestões anteriores não foram mantidas. Além de buscar soluções imediatistas, como a tentativa de empurrar as festas para outros locais mais distantes, ocorreu uma burocratização dos processos de uso de espaços e, de certa forma, a priorização do setor privado que, já atento ao sucesso do formato desses eventos, passou a tentar cooptar a cena por meio de grandes festas e festivais.

É possível verificar uma pressão de empresários que controlavam esse mercado, por meio da ANEP (Associação da Noite e Entretenimento Paulistano), para complicar e inviabilizar 0 acontecimento das festas. A ANEP reúne promotores de eventos e donos de grandes casas noturnas (como D-Edge, Lions, The Week), com 0 objetivo de representar estabelecimentos de lazer e entretenimento no debate com o poder público. 
Entretanto, segundo os atores envolvidos nas festas de rua aqui analisadas, essa entidade não mantém diálogo com os coletivos e sua atuação; já que é focada nos negócios formais, leva os coletivos para a marginalidade e a invisibilidade.

Um campo de batalha se formou. Algumas festas que já haviam conseguido alvarás foram impedidas de acontecer; outras receberam multas ou a tiveram a presença da polícia acionada por moradores; houve até mesmo casos de organizadores das festas recebendo ameaças anônimas. No centro da cidade, os coletivos que cresceram de forma orgânica e, já habituados com verba que apenas viabilizava os projetos, foram driblando os acontecimentos para poderem permanecer. Hoje carregam o desafio de darem continuidade a esses movimentos espontâneos, que estão entrelaçados com demandas da própria sociedade e que precisam ser preenchidas. As ações dos coletivos envolvem gestão, organização, negociação, criação, articulação, engajamento, apropriação etc. Em suma, proporcionam uma rica experiência em sua totalidade e estabelecem um novo ethos que conjuga atividade artística, a música como porta-voz dessas questões, uma economia política dessa nova cena e formas de resistência às lógicas do capital internacional. Como aponta Hessel (2011),

a nossa capacidade de indignação pode e deve levar-nos a ações construtivas motivadas pela recusa da passividade e da indiferença. Saber dizer não. Denunciar. Protestar. Resistir. Indignar-nos. Desobedecer, por vezes, ao que não nos parece justo e que põe em causa as liberdades e os direitos fundamentais. Saber dizer sim. Agir. Combater. Participar da insurreição pacífica que nos permite dar resposta a um mundo que não nos agrada. Numa palavra: empenharmo-nos! (p.23)

\section{Os coletivos e as festas}

A partir de uma pesquisa de base etnográfica (que inclui diário de campo e entrevistas com produtores e frequentadores), tentamos compreender esse fenômeno recente das festas de rua em São Paulo, na busca de indícios desse engajamento musical. Para tanto, analisamos três coletivos - Síntese Coletiva, Mamba Negra e Autônoma-Atemporária - que, de forma complementar, dão-nos pistas sobre como se organizam, quais são seus propósitos e os desdobramentos de suas ações.

\section{SÍNTESE COLETIVA}

0 Síntese Coletiva começou em 2016 a partir de um workshop no MIS - Museu da Imagem e do Som - com o intuito de suprir uma carência formativa de música eletrônica. Na sequência, levou o público para um estúdio, para que pudesse vivenciar 0 cotidiano de produção, realizando em conjunto um bazar de troca de equipamentos.

Depois vieram as festas com performances ao vivo: já ocorreram várias em casas noturnas, na rua, em prédios abandonados, em ocupações de escolas e de prédios. Outros coletivos foram formados a partir desse que se mostra como um 
ambiente de diálogo de artistas - desde os que estão começando até os profissionais -, no mesmo palco, com condições e oportunidades similares. Nos espaços culturais, o grupo já tem envolvido outros coletivos de malabares, de rap, do funk.

\section{Mario Dal Santo faz a curadoria e a gestão e} conta com o Conselho Ancião, composto por oito membros. Qualquer pessoa pode participar, segundo eles, bastando enviar um portfólio e preencher um cadastro, pois o objetivo é a propagação do conhecimento sem fins lucrativos, já que tem um caráter inclusivo. 0 perfil do público não pode ser definido por classe: são pessoas com escolaridade razoável, conhecimento de música e de informática, têm em média vinte e cinco anos, sendo vinte por cento feminino. 0 coletivo é composto por produtores, aficionados por música e consumidores.

No geral, como dizem os organizadores, os eventos só dão prejuízo. A verba que entra é direcionada para 0 orçamento anual e, atualmente, 0 dinheiro vem dos editais. Dal Santo é proprietário do Santo Studio, e os equipamentos viabilizam os eventos; outro membro do grupo é proprietário do Estúdio Aurora. A divulgação das festas é feita pelas redes sociais e pelos artistas que se apresentam. As festas independentes precisam de autorização da prefeitura - e, depois, dos bombeiros, da polícia, da CET - e pode levar até noventa dias para ser obtida. Pagam-se algumas taxas e, para que ocorra no espaço público, as festas devem ser gratuitas, podendo ter um patrocinador. Eles nos contam que, se a festa ocorrer na Avenida Paulista, adotam a tática de não divulgar nas redes sociais, pois 0 evento deve figurar como manifestação espontânea e não como algo programado.

A página do Facebook ${ }^{10}$ do Síntese Coletiva possui 1.253 membros e concentra toda a comunicação do grupo. Lá se podem ver dicas de cursos, compra, uso, aluguel e venda de equipamentos ou de como montar shows. Ali também são disponibilizados tutoriais de sintetizadores e várias novidades de softwares e plug-ins, sendo lugar também para solução de dúvidas e para compartilhamento das produções dos participantes.

\section{MAMBA NEGRA}

Muitas das pessoas que hoje atuam nesses coletivos têm uma relação direta com a luta pelos espaços públicos da cidade - tanto nas ocupações, na luta pela gratuidade no transporte coletivo, na juventude secundarista contra a Copa e as Olimpíadas, na luta LGBTT, ou nos coletivos pretxs. A Mamba Negra, projeto dirigido por Carol Schutzer e Laura Diaz, é parte de um movimento cultural independente - como salientam - e se alinha na defesa da liberdade 
com quem está nas lutas. A Mamba vem criando maneiras de organização, trabalho e intervenção urbana, e a principal ação - a festa - nasceu com a proposta de criação de espaços de experimentação artística e política, atuando no centro velho de São Paulo para explorar ambientes mal utilizados da metrópole - o que elas chamam de "cicatrizes geradas pelo plano urbanístico falho e a especulação imobiliária”.

Em quase uma centena de festas, houve edições gratuitas no Largo São Francisco, debaixo do Viaduto do Chá, na ocupação do MSTS (Movimento Sem Teto de SP) no Cine Marrocos, no Centro Cultural Ouvidor 63 (prédio do governo do Estado ocupado há três anos por artistas) e na Casa Florescer (centro de acolhida para mulheres trans e travestis). Em paralelo, a Mamba também realiza festas pagas, que geralmente acontecem em galpões e vilas industriais e, às vezes, são posteriores aos eventos na rua, chamadas de after, sendo usadas para custear os eventos gratuitos.

Até 0 segundo ano de festa, Schutzer e Diaz absorviam todas as funções de criação de conteúdo, produção artística e executiva, gestão financeira, montagem, técnica, iluminação. Com o passar do tempo o projeto cresceu, e muita gente se aproximou do coletivo, o que proporcionou a elas a possibilidade de estruturar uma equipe sólida. Hoje, o custo para realizar uma festa para cerca de 1.500 pessoas pode chegar a $\mathrm{R} \$ 100$ mil. 0 público parece uma conjunção de vários movimentos alternativos e, no geral, atua numa cumplicidade ativista com a festa. A página no Facebook ${ }^{11}$ da Mamba Negra tem mais de 30 mil curtidas.

Além disso, é uma teia de ações, tendo se associado, por exemplo, à Coletividade Namíbia (grupo que reúne artistas negros LGBTQI+ que atuam em artes visuais, música, dança, moda e teatro), que se tornou responsável pelas performances das festas. Em 2017, também foi implementada a lista VIP para transgêneros, cadeirantes e para quem vai de bicicleta. Outra iniciativa foi a criação de um selo musical para lançamentos de produtores que permeiam as festas e estão fora do circuito comercial.

\section{AUTÔNOMA-ATEMPORÁRIA}

0 coletivo A-Temp é um braço da Voodoohop; "um galho da mesma árvore", afirma Diogo Jacquard. Foi um fluxo que começou em 2016 e que tem como propósito a resistência ao mundo ou uma gentrificação ao contrário, como dizem. Na época, o grupo buscava os lugares que ninguém frequentava, por medo da violência e dos moradores de rua, e ocupava só pelo exercício de ocupar, sem pedir autorizações e fazendo festas sem fins lucrativos. 
Entendendo a celebração como uma questão cultural, o coletivo verificava que as pessoas já não saíam para as ruas, aprisionadas em locais fechados, como nos conforme disse Jacquard. Assim, passaram a procurar lugares nos quais se pudessem fazer festas. Um exemplo foi a Avenida Paulista, que desde 2016 é fechada para carros aos domingos; por conta disso, outras ruas ao redor ficam inativas e podem ser usadas para as festas. Fazem festas no túnel embaixo da Praça do Ciclista (via de ligação da zona oeste com a Avenida Paulista) e instruíram as pessoas a usarem os bares e banheiros da região, complementando uma infraestrutura da própria cidade para que a festa acontecesse.

0 coletivo tem seis membros, mas atinge aproximadamente um grupo de quinze pessoas, e os envolvidos fazem tudo e se complementam. Um trabalha com software, outro tem sistema de som e um gerador de energia, outro é fotógrafo, e quase todos são artistas. Fazem um ativismo intenso no próprio jeito de ser e produzir arte, remixes, fazer curadoria da programação etc. 0 som predominante na festa é deep house e techno - uma nuance sonora entre a Mamba Negra e a Voodoohop.
0 grupo, que já teve festas impedidas pela polícia, sempre tenta negociar. Dentre outros casos, contam que, certo dia, foram fazer uma festa na Praça Roosevelt e, quando chegaram, a polícia já os estava aguardando. "0 policial chegou e disse: 'nem sei por que estou aqui, mas você vai ter que abaixar o som ou mudar de lugar"', relata um dos organizadores. Geralmente fazem festas no Minhocão, onde é permitido, e participaram pela primeira vez de um edital para o SP na Rua ${ }^{12}$ em 2017.

Possuem na sua estrutura uma "tenda de redução de danos", para orientar as pessoas que já beberam ou se drogaram muito, além de barracas de massagem e de lanches. A divulgação é feita pelo Facebook ${ }^{13}$ (na sua página, que tem 1.730 participantes) e no "boca a boca". Como podem sofrer impedimentos de realização, mantêm notícias em tempo real para o público, divulgando o local apenas algumas horas antes da festa.

\section{Usos do espaço e dos corpos na cidade}

As ações dos coletivos analisados salientam
os sentidos políticos de tais práticas lúdicas e
festivas, tanto por estarem articuladas a grupos Paulo, reunindo coletivos, núcleos e artistas em ruas e pontos históricos do Centro antigo, comemorando o Mês da Cultura Independente (MCI), que existe há 10 anos. Segundo Assef (2016), no ano de 2016, a Secretaria recebeu quase 300 inscrições para participar do evento SP na Rua, tendo escolhido 57 propostas que foram divididas entre 25 espaços e ações itinerantes. Com duração de mais de 10 horas, o evento conta com música, projeções, instalações e intervenções artísticas. 
e minorias discriminadas e pouco representadas na cena eletrônica, como trans ou pretxs (no caso mais específico da Mamba Negra); pelas formas mais autogestionárias, colaborativas e horizontais de produzir e divulgar a música eletrônica (mais enfatizadas pelo Síntese Coletiva); como também nas maneiras de pensar e usar os espaços públicos de São Paulo, os ocos da cidade esvaziados pelo medo urbano e pelas lógicas econômicas que valorizam os locais fechados, higienizados e controlados (no caso do coletivo A-Temp).

Em todos, a relação com as institucionalidades (seja a Prefeitura, os editais públicos de financiamento ou a ANEP) mostra-se como negociação, buscando e inventando caminhos para fazer usos astuciosos (CERTEAU, 1994) frente às atuações pautadas nas estratégias de quem detém o poder e a hegemonia. Nessa disputa, avanços, recuos, seduções e resistências vão se desenhando em caminhos não previamente planejados, mas que fazem parte do cotidiano das ações desses grupos, reinventando o fazer político na pluralidade e na ampliação do acesso à vida urbana e à ocupação dos espaços fraturados da cidade. Mais ainda, eles veem a necessidade do fortalecimento das redes de colaboração e articulação entre si como a via mais efetiva para suas atuações e sua forma de luta, uma vez que "as forças mais conservadoras já estão organizadas e em consonância, buscando esvaziar o próprio conceito de cidade", no dizer das organizadoras do Mamba Negra. Um exemplo disso pode ser visto na lei recentemente aprovada, que disciplina o Plano Municipal de Desestatizaçã $0^{14}$, prevendo a concessão de parques, terminais de ônibus, mercados municipais e outros bens da cidade para a iniciativa privada.

Vão se elaborando, desta maneira, formas de atuação, organização, produção e acontecimento dessas festas de rua, em que todos (seja quem produz, organiza, toca ou dança) são participantes de um mesmo projeto e ideário, e fazem daquele momento uma brecha na rotina dos espaços centrais da cidade, ocupados por outros usos, transformados em territórios alternativos (HAESBAERT, 2002) por ações momentâneas e moleculares. É aquilo que González-Victória (2011) chama de "arte de ação", que se ancora e efetiva no corpo (humano, mas também da cidade, acrescentamos) ressignificando-o e atuando como fator de reconhecimento individual e coletivo, ocupando e habitando a cidade e suas cicatrizes e vazios. Ainda que haja questões mais específicas levantadas e trabalhadas em cada um desses coletivos analisados, em todos os casos há uma busca por formas lúdicas e festivas de estar juntos e ocupar e fazer uso da cidade, em que 0 jogo performativo é parte fundamental nessa produção estética cuja centralidade é a festa. Trata-se de uma noção de estética desvinculada da noção 
clássica legitimada, mas pensada como criação de modos de ser, viver, experimentar o cotidiano e criar laços: a conotação política que aqui enfatizamos nessas festas, em que a "partilha do sensível" (RANCIÉRE, 2009) e uma "ética da estética" (MAFFESOLI, 2005), são os elementos de um ethos pautado na criatividade e na busca do sentir em comum, uma vez que nesses eventos coletivos torna-se possível dar significado e sentido às experiências individuais e coletivas do corpo, das identidades, da cidade, dos afetos.

Essa efetivação corporal inscrita no cotidiano tem a ver com a noção de corpografia urbana, que, como ressalta Jacques (2008), seria um tipo de cartografia realizada pelo e no corpo, em que a memória e as vivências urbanas estariam inscritas nos corpos como registros de suas experiências na cidade; uma espécie de grafia urbana que fica inscrita, mas também configura o corpo de quem a experimenta. Nessa simbiose entre os corpos e a cidade, tem-se a dimensão espacial como fundamental para a compreensão da vida urbana e da vida em sociedade.

0 espaço aqui é como esfera da possibilidade de existência da multiplicidade, de distintas trajetórias e muitas vozes, em que ele é produto das inter-relações, dos fluxos e nunca está finalizado ou pronto, mas sempre em dinâmica elaboração, conforme Massey (2005). Como supõe a autora, assim como temos que pensar num antiessencialismo em relação às identidades (étnicas, de gênero etc.), as quais devem ser compreendidas como um processo, também é preciso refletir sobre o espaço nessa mesma lógica, até porque ele faz parte da formação e do processo destas mesmas subjetividades políticas.

0 reconhecimento da diversidade e da construção da diferença passa pelo reconhecimento da espacialidade. Ora, essa noção da preponderância da espacialidade (para além da separação tempo versus espaço à moda kantiana) como um devir, advinda da geografia cultural, inspira-nos a considerar ainda mais a dimensão política dos espaços ou dos territórios, como lócus dos usos, dos afetos, das memórias, das disputas, das experiências, dos encontros, das partilhas e das possibilidades.

Como já afirmava Lefebvre (2013) na década de 1970, o espaço pode ser pensado em uma concepção triádica, na distinção entre prática espacial, espaços de representação $\mathrm{e}$ representação do espaço. A "prática espacial" (ou espaço vivido) corresponde ao espaço percebido e é aquele mais próximo à vida cotidiana e dos usos ordinários em que se desenrolam as atividades diárias nas práticas dos habitantes e forâneos da cidade. Por sua vez, os "espaços de representação" (ou espaço sensorial/sensual das imagens, vozes, palavras, sons, cheiros, [con]tatos) são os que envolvem os espaços físicos sobrepostos pelos sistemas simbólicos complexos que os codificam e os convertem numa miríade de imagens e imaginários. Além do espaço dos habitantes e usuários, é também o espaço daqueles que 
inventam e criam (sejam artistas, errantes, participantes das festas) e nos quais há um jogo em que podem estar presentes tanto códigos impostos desde cima por parte dos dominantes, como também aquelas práticas que bebem e se inspiram nas desobediências e que habitam um lado mais clandestino e subterrâneo da vida. Junto a esses dois espaços (percebido e vivido) há a "representação do espaço" (ou espaço concebido), entrelaçado aos dois primeiros por sua ambição de sempre se impor e prevalecer sobre eles, pois diz respeito às relações de poder advindas da ordem (Estado, mercado, urbanismos), que busca se estabelecer inclusive pela violência, e é ideológico porque disfarçado atrás de discursos técnicos, frios e periciais que se querem inquestionáveis para controlar o que se quer diferente e insubordinado.

Ora, essa concepção politizada do espaço ajuda-nos a compreender, como sugere Massey (2005), a espacialidade como uma fonte para a produção de novas trajetórias, novos espaços de representação sensoriais a afetivos, novas identidades, novas relações e novas diferenças, abrindo lugar para maneiras renovadas do político, as quais se alimentam dos distintos relatos e das reinvindicações da cidade, como aqui temos visto nas festas de rua e nas ações dos coletivos abordados.

\section{Considerações finais}

A partir da atuação dos coletivos juvenis e das festas mencionadas, buscamos neste artigo refletir sobre as articulações complexas entre espaços públicos, espacialidades, usos da cidade, culturas juvenis e as práticas musicais, em que as corporalidades e os afetos ganham especial atenção.

Pensar na inter-relação entre espaços e subjetividades é um caminho que nos parece profícuo neste sentido. Vinculadas a um certo "giro sensorial" ou "affective turn" dentro das humanidades desde os anos 1990 (GREGG; SEIGWORTH, 2010), a questão do corpo, dos sentidos e dos afetos relacionados às práticas artísticas em geral ganham protagonismo, associados às noções de performance $\mathrm{e}$ performatividade (TAYLOR, 2011). Estas são compreendidas como categorias epistêmicas que poderiam escapar das lógicas hegemônicas ocidentais, logocêntricas, racionalizantes e coloniais. Ou, como sugere Maffesoli (1998), seria a promoção de uma razão sensível, que, longe de opor atos afetivos e atos cognitivos, trabalha os elos que os articulam numa cadeia dinâmica.

Os usos e as ocupações dos espaços públicos e das cidades por estas festas evidenciam a capacidade artística, estética e sensível de reconfigurar o político e as próprias urbes, reinventando usos, trajetos, territórios e evidenciando seu caráter relacional, de local de agenciamentos e comunicação. É uma experimentação de formas de estar juntos e partilhar experiências que se valem do fugaz, do fluxo, do interacional e das ações coletivas, 
nas quais a música e suas práticas atuam na elaboração de novas formas de cidadania.

Como tem apontado Harvey (2014), Delgado (2007) e Borja (2003), a questão da reivindicação urbana mostra-se, nos últimos anos, moduladas a redes mais amplas de indignação, de tomada das ruas, de articulações entre estética e política e maneiras de atuar políticamente, que se querem mais horizontais e não institucionalizadas. 0 que percebemos, neste contexto dos coletivos analisados, é que suas práticas já chamam a atenção tanto do poder público - no sentido de coibi-los - e do mercado - no sentido de cooptálos - dada a força e a potência desse movimento das festas e seus desdobramentos.

Esboçam-se, assim, elementos percebidos nas práticas musicais-midiáticas alternativas/ autorais que analisamos na contemporaneidade, em que se conjugam funções estéticas, sociais e políticas. Nestas, formas de consumo cultural, performatividade de identidades e construção de socialidades constituem 0 élan social entre produtores e frequentadores das festas e os locais de encontro que aqui analisamos.

Esse deslocamento da cena de música eletrônica, em São Paulo, dos clubes para as ruas, parece oferecer pistas para compreendermos sentidos de uma certa "re-energização do underground" (na fala dos próprios atores) e sua capacidade contrahegemônica e resistente. Se essas características, ligadas a uma discussão sobre subculturas e resistência, já suscitaram críticas - por seus aspectos insuficientes para a compreensão de cenas musicais mais fluidas e em negociação com elementos do mainstream e ligadas ao consumo na contemporaneidade - as festas e os coletivos aqui analisados parecem desafiar esses caminhos críticos, fazendo-nos repensar as noções de underground e sua validade. Assunto, talvez, para outras e futuras conversas.

\section{Referências}

AMARAL, Adriana. Subculturas e cibercultura(s): para uma genealogia das identidades de um campo. FAMECOS - mídia, cultura, tecnologia v.15 n.37, 2008. Uma breve introdução à subcultura cyberpunk. Estilo, alteridade, transformações e hibridismo na cibercultura. E-Compós. n. 2. v.22. 2005.

ASSEF, Claudia. Com festas de dub a techno, SP na Rua comprovou que São Paulo pode ser a cidade mais legal do mundo. Musicnonstop. 11/09/2016. Disponível em: https://musicnonstop.uol.com.br/com-festas-de-dub-atechno-sp-na-rua-comprovou-que-sao-paulo-pode-ser-acidade-mais-legal-do-mundo/. Acesso em janeiro 2018.

BORJA, Jordi. La ciudad conquistada. Madrid: Alianza, 2003.

CERTEAU, Michel de. A invenção do cotidiano Artes de Fazer vol.1. Petrópolis: Vozes, 1994.

CHIAVERINI, Tomás. Festa Infinita: 0 entorpecente mundo das raves. São Paulo: Ediouro, 2008.

DELGADO, Manuel Sociedades movedizas: pasos hacia una antropología de las calles. Barcelona: Anagrama, 2007.

FREIRE FILHO, João. Das subculturas às pós-subculturas juvenis: música, estilo e ativismo político. Contemporânea - Revista de Comunicação. v.3, n.1, 2005. 
GONZÁLEZ-VICTORIA, Luis. Artes de acción: resignificación del cuerpo y el espacio urbano.

Revista Nodo. n. 10, v.5, 2011. p. 55-72.

GREGG, Melissa; SEIGWORTH, Gregory (eds.).

The Affect theory reader. Durham: Duke University Press Books, 2010.

HAESBAERT, Rogerio. Territórios alternativos.

São Paulo/Rio de Janeiro: Contexto/EdUFF, 2002.

HARVEY, David. Cidades Rebeldes. São Paulo:

Martins Fontes, 2014.

HESSEL, Stéphane. Empenhai-vos - conversa com Gilles Vanderpooten. Portugal: Editora Planeta, 2011.

JACQUES, Paola B. Corpografias urbanas. V ENECULT

- Encontro de Estudos Multidisciplinares em

Cultura. 28 a 30 de maio de 2008. Faculdade de Comunicação/UFBA, Salvador/Bahia. Disponível em: < http://www.cult.ufba.br/enecult2008/14401-03.pdf> Acesso em: Fev. de 2018.

LEFEBVRE, Henri. La producción del espacio. Madrid: Capitán Swing Libros, 2013.

0 direito à cidade. São Paulo: Centauro, 2001.

LEMOS, André. Cibercultura: alguns pontos para compreender a nossa época. In: LEMOS, André; CUNHA, Paulo (orgs). Olhares sobre a cibercultura. Porto Alegre: Sulina, 2003.

LIPOVETSKY, Gilles. A felicidade paradoxal: ensaio sobre a sociedade de hiperconsumo. São Paulo: Companhia das Letras, 2007.

MAFFESOLI, Michel. A ética da estética. In: 0s mistérios da conjunção: ensaios sobre comunicação e socialidade. Porto Alegre: Sulina, 2005.

Elogio da razão sensível. Petrópolis: Vozes, 1998.

MARKE, Eric. MEB - A história da música eletrônica brasileira. São Paulo: LiteraRUA, 2017.
MASSEY, Doreen. Filosofia y politica de la espacialidade - algunas consideraciones. In: ARFUCH, Leonor (org.)

Pensar este tempo: espacios, afectos, pertenencias. Buenos Aires: Paidós, 2005.

PEREIRA, Simone Luci. Circuito de festas de música "alternativa" na área central de São Paulo: cidade, corporalidades, juventude. FAMECOS - mídia, cultura, tecnologia. v.24, n.2, 2017.

RANCIERE, Jacques. A partilha do sensível: estética e política. São Paulo: Ed. 34, 2009.

REIA, Jhessica. Ritmos da cidade: som, regulação e persistência da música de rua. Trabalho apresentado no GP Comunicação e Estudos de som e Música, Compós2018. Anais.... Belo Horizonte. Junho/2018.

SÁ, Simone Pereira de. Música eletrônica e tecnologia: reconfigurando a discotecagem. In: LEMOS, André; CUNHA, Paulo (orgs). Olhares sobre a cibercultura. Porto Alegre: Sulina, 2003.

TAYLOR, Diana. Performance, teoría y práctica. In: TAYLOR, Diana y FUENTES, M. (eds.) Estudios avanzados de performance. México: Fondo de Cultura Economica/Instituto Hemisférico de Performance y Política; New York: New York University, 2011.

THORNTON, Sarah. Club cultures: music, media and subcultural capital. Connecticut: Wesleyan University Press, 1996.

WOODSIDE, Julian; JIMENEZ, Claudia. Creación, socialización y nuevas tecnologías en la producción musical. In: GARCÍA CANCLINI, Nestor et al (eds.) Jóvenes, Culturas Urbanas y Redes Digitales. Madri: Ariel/Telefônica, 2012. 


\section{Collectives of electronic dance music in São Paulo: uses of the city, youth cultures and political senses}

\section{Abstract}

We analyzed a recent electronic dance music scene that has been taking place on the streets of the central areas of São Paulo articulated to the discussions and actions that took place in the city about its uses and about urban citizenship.

The music centrality and its communicational and political dimension are evidenced: dance, body and performativity of the identities allied to the construction of ways to be together and occupy the city. The methodology focuses on ethnography and we analyzed the actions of three groups linked to this scene in São Paulo. As results we present some unfolding and political meanings generated there: collaborative forms and self-management; ways of occupying public spaces and claiming the right to the city; ludic and affective dimensions.

\section{Keywords}

Electronic music. City. Youth Cultures.

\section{Colectivos de música electrónica de} pista en São Paulo: usos de la ciudad, culturas juveniles y sentidos políticos

\section{Resumen}

Analizamos una reciente escena de la música electrónica de pista que viene ocurriendo en las calles de las áreas centrales de São Paulo articulada a las discusiones y acciones ocurridas en la ciudad sobre sus usos y sobre ciudadanía urbana. Se evidencia la centralidad de la música y su dimensión comunicacional y política: danza, cuerpo y performatividad de las identidades aliadas a la construcción de modos de estar juntos y ocupar la ciudad. La metodología se centra en la etnografía y enfocamos las acciones de tres colectivos ligados a esta escena en São Paulo. Como resultados presentamos algunos desdoblamientos y sentidos políticos ahí engendrados: formas colaborativas y autogestionarias; maneras de ocupar los espacios públicos y reivindicar el derecho a la ciudad; las dimensiones lúdicas y afectuales allí presentes.

\section{Palabras-clave}

Música electrónica. Ciudad. Culturas juveniles. 


\section{Expediente}

A revista E-Compós é a publicação científica em formato eletrônico da Associação Nacional dos Programas de Pós-Graduação em Comunicação (Compós). Lançada em 2004, tem como principal finalidade difundir a produção acadêmica de pesquisadores da área de Comunicação, inseridos em instituições do Brasil e do exterior.

\section{E-COMPÓS I www.e-compos.org.br I E-ISSN 1808-2599}

Revista da Associação Nacional dos Programas de Pós-Graduação em Comunicação. Brasília, v.21, n.3, set/dez. 2018. A identificação das edições, a partir de 2008, passa a ser volume anual com três números. Indexada por Latindex I www.latindex.unam.mx

\section{CONSELHO EDITORIAL}

Ada Cristina Machado Silveira, Universidade Federal de Santa Maria, Brasi Alda Cristina Silva da Costa, Universidade Federal do Pará, Brasil Alfredo Luiz Paes de Oliveira Suppia, Universidade Estadual de Campinas, Brasil Ana Carolina Rocha Pessôa Temer, Universidade Federal de Goiás, Brasil Ana Regina Barros Rego Leal, Universidade Federal do Piauí, Brasil André Luiz Martins Lemos, Universidade Federal da Bahia, Brasil Angela Cristina Salgueiro Marques, Universidade Federal de Minas Gerais, Brasil Ângela Freire Prysthon, Universidade Federal de Pernambuco, Brasil Anna Cristina Pertierra, Western Sidney University, Austrália Antonio Carlos Hohlfeldt, Pontifícia Universidade Católica do Rio Grande do Sul, Brasi Arthur Ituassu, Pontifícia Universidade Católica do Rio de Janeiro, Brasil Bruno Campanella, Universidade Federal Fluminense, Brasil Bushra Hameedur Rahman, University of the Punjab, Paquistão, Paquistão Cárlida Emerim, Universidade Federal de Santa Catarina, Brasil Carlos Del Valle Rojas, Universidad de La Frontera, Chile Carlos Eduardo Franciscato, Universidade Federal de Sergipe, Brasil Cláudio Novaes Pinto Coelho, Faculdade Cásper Líbero, Brasil Danilo Rothberg, Universidade Estadual Paulista, Brasil Denise Tavares, Universidade Federal Fluminense, Brasil Diógenes Lycarião, Universidade Federal do Ceará, Brasil Dóris Martínez Vizcarrondo, Universidad de Puerto Rico Mayagüez, Porto Rico Eduardo Vicente, Universidade de São Paulo, Brasil

Eliza Bachega Casadei, Escola Superior de Propaganda e Marketing - SP, Brasil Elvira Gomes dos Reis Freitas, Universidade de Cabo Verde, Cabo Verde Eneus Trindade, Universidade de São Paulo, Brasil Erick Felinto de Oliveira, Universidade do Estado do Rio de Janeiro, Brasil Erick Torrico, Universidad Andina Simón Bolívar, Bolívia, Bolívia Erly Vieira Júnior, Universidade Federal do Espírito Santo, Brasil Fabio La Rocca, Université Paul-Valéry Montpellier 3, França Fernando Firmino da Silva, Universidade Federal da Paraíba, Brasil Francisco de Assis, FIAM-FAAM Centro Universitário, Brasil Francisco Elinaldo Teixeira, Universidade Estadual de Campinas, Brasil Francisco Gilson Rebouças Pôrto Junior, Universidade Federal do Tocantins, Brasil Francisco Sierra Caballero, CIESPAL, Equador Frederico de Mello Brandão Tavares, Universidade Federal de Ouro Preto, Brasil Gabriela Reinaldo, Universidade Federal do Ceará, Brasil Germán Rey Beltrán, Universidad Nacional de Colombia, Colômbia Gilson Vieira Monteiro, Universidade Federal do Sul da Bahia, Brasil Gustavo Daudt Fischer, Universidade do Vale do Rio dos Sinos, Brasil Gustavo Hernández Díaz, Universidad Central de Venezuela, Venezuela Heidi Figueroa Sarriera, Universidad de Puerto Rico, Porto Rico Ignacio Aguaded, Universidad Huelva, Espanha Inesita Soares de Araújo, FIOCRUZ, Brasil Itania Maria Mota Gomes, Universidade Federal da Bahia, Brasil Jiani Adriana Bonin, Universidade do Vale do Rio dos Sinos, Brasi João Carlos Ferreira Correia, Universidade da Beira Interior, Portugal Jonathan Cohen, University of Haifa, Israel José Afonso da Silva Junior, Universidade Federal de Pernambuco, Brasil José Luiz Aidar Prado, Pontifícia Universidade Católica de São Paulo, Brasil Josette Maria Monzani, Universidade Federal de São Carlos, Brasil Juçara Gorski Brittes, Universidade Federal de Ouro Preto, Brasil Julián Durazo Hermann, Université du Québec à Montreal, Canadá Juliana Freire Gutmann, Universidade Federal da Bahia, Brasil
Karla Yolanda Covarrubias, Universidad de Colima, México Laura Loguercio Cánepa, Universidade Anhembi Morumbi, Brasil Leonel Azevedo de Aguiar, Pontifícia Universidade Católica do Rio de Janeiro, Brasil Leticia Cantarela Matheus, Universidade do Estado do Rio de Janeiro, Brasil Ling Chen, Hong Kong Baptist University, China Luciana Coutinho Souza, Universidade de Sorocaba, Brasil Marcel Vieira Barreto Silva, Universidade Federal da Paraíba, Brasil Marcia Tondato, Escola Superior de Propaganda e Marketing, Brasil Márcio Souza Gonçalves, Universidade do Estado do Rio de Janeiro, Brasil Maria Ataide Malcher, Universidade Federal do Pará, Brasil Maria das Graças Pinto Coelho, Universidade Federal do Rio Grande do Norte, Brasi Maria Elena Hernández Ramirez, Universidad de Guadalajara, México Maria Elisabete Antonioli, Escola Superior de Propaganda e Marketing - SP, Brasil Maria Teresa Quiroz, Universidad de Lima, Peru Marialva Carlos Barbosa, Universidade Federal do Rio de Janeiro, Brasil Marina Poggi, Universidad Nacional de Quilmes, Argentina Marli Santos, Faculdade Cásper Líbero, Brasil Mateus Yuri Passos, Universidade Metodista de São Paulo, Brasil Mauricio Mario Monteiro, Universidade Anhembi Morumbi, Brasil, Brasil Mayka Castellano, Universidade Federal Fluminense, Brasil Mirta Varela, Universidad de Buenos Aires, Argentina

Mozahir Salomão Bruck, Pontifícia Universidade Católica de Minas Gerais, Brasil Neyla Graciela Pardo Abril, Universidad Nacional de Colombia, Colômbia Nísia Martins Rosario, Universidade Federal do Rio Grande do Sul, Brasil Olga Guedes Bailey, Nottingham Trent University, Reino Unido Paolo Demuru, Universidade Paulista, Brasil

Paolo Peverini, LUISS, Itália

Paško Bilić, Institute for Development and International Relations, Croácia Paula Melani Rocha, Universidade Estadual de Ponta Grossa, Brasil Potiguara Mendes Silveira Jr, Universidade Federal de Juiz de Fora, Brasil Rafael Cardoso Sampaio, Universidade Federal do Paraná, Brasil Rafael Tassi Teixeira, Universidade Tuiuti do Paraná, Brasil Regiane Lucas de Oliveira Garcêz, Universidade Federal de Minas Gerais, Brasil Regiane Regina Ribeiro, Universidade Federal do Paraná, Brasil Renata Pitombo Cidreira, Universidade Federal do Recôncavo da Bahia, Brasil Renato Essenfelder, Escola Superior de Propaganda e Marketing, Brasil Roberto Elísio dos Santos, Universidade Municipal de São Caetano do Sul, Brasil Robson Borges Dias, Universidade Católica de Brasília (UCB), Brasil Rodolfo Rorato Londero, Universidade Estadual de Londrina, Brasil Rosario Sanchéz Vilela, Universidad Católica del Uruguay, Uruguai Roseli Figaro, Universidade de São Paulo, Brasil Saima Saeed, Jamia Millia Islamia, India Sara Brandellero, Leyden University, Holanda Simone Maria Andrade Pereira de Sá, Universidade Federal Fluminense, Brasil Sônia Caldas Pessoa, Universidade Federal de Minas Gerais, Brasil Sun Sun Lim, Singapore University of Technology and Design, Singapura Tatiana Oliveira Siciliano, Pontifícia Universidade Católica do Rio de Janeiro, Brasil Thaïs de Mendonça Jorge, Universidade de Brasília, Brasil Valquiria Michela John, Universidade Federal do Paraná, Brasil Vicky Mayer, Tulane University, Estados Unidos da América do Norte Yamile Haber Guerra, Universidad de Oriente, Cuba 


\section{CONSELHO CIENTÍFICO}

Cristiane Freitas Gutfreind, Pontifícia Universidade Católica do Rio Grande do Sul, Brasil I Eduardo Antonio de Jesus, Universidade Federal de Minas Gerais, Brasil I Eduardo Morettin, Universidade de São Paulo, Brasil I Irene de Araújo Machado, Universidade de São Paulo, Brasil

\section{COMISSÃO EDITORIAL}

Igor Pinto Sacramento, Universidade Federal do Rio de Janeiro, Brasil I Kelly Cristina de Souza Prudencio, Universidade Federal do Paraná, Brasil | Miriam de Souza Rossini, Universidade Federal do Rio Grande do Sul, Brasil

\section{EDITORES ASSOCIADOS}

Rafael Grohmann, Faculdade Cásper Líbero, Brasil I Thaiane Moreira de Oliveira, Universidade Federal Fluminense, Brasil

\section{CONSULTORES AD HOC}

Ada Machado, Universidade Federal de Santa Maria, Brasil | Ana Carolina Escosteguy, Universidade Federal de Santa Maria, Brasil | Andrea França, Pontifícia Universidade Católica do Rio de Janeiro, Brasil | Ariane Holzbach, Universidade Federal Fluminense, Brasil | Benjamim Picado, Birkbeck College, Inglattera | Bruno Souza Leal, Universidade Federal de Minas Gerais, Brasil I Eduardo Morettin, Universidade de São Paulo, Brasil I Felipe Trotta, Universidade Federal Fluminense, Brasil | Francisco Rüdiger, Pontifícia Universidade Católica do Rio Grande do Sul, Brasil | Gislene da Silva, Universidade Federal de Santa Catarina, Brasil | Inês Vitorino, Universidade Federal do Ceará, Brasil I Isaltina Gomes, Universidade Federal de Pernambuco, Brasil I Jairo Ferreira, Universidade do Vale do Rio dos Sinos, Brasil I Karina Janz, Universidade Estadual de Ponta Grossa, Brasil | Kati Caetano, Universidade Tuiuti do Paraná, Brasil | Lilian França, Universidade Federal do Sergipe, Brasil | Liziane Guazina, Universidade de Brasília, Brasil I Márcio de Vasconcellos Serelle, Pontifícia Universidade Católica de Minas Gerais, Brasil I Marta Maia, Universidade Federal de Ouro Preto, Brasil I Maurício de Bragança, Universidade Federal Fluminense, Brasil I Nina Velasco e Cruz, Universidade Federal de Pernambuco, Brasil | Norval Baitello Jr., Pontifícia Universidade Católica de São Paulo, Brasil | Pedro Guimarães, Universidade do Estado do Rio de Janeiro, Brasil | Priscilla Perazzo, Universidade Municipal de São Caetano do Sul, Brasil I Sofia Zanforlin, International Association of Media and Communication Research, Estados Unidos I Talitha Ferraz, Escola Superior de Propaganda e Marketing, Brasil I Tattiana Teixeira, Universidade Federal de Santa Catarina, Brasil I Victa de Carvalho Pereira da Silva, Universidade Federal do Rio de Janeiro, Brasil

\section{EQUIPE DE EDITORAÇÃO}

ASSISTENTE EDITORIAL Marcio Telles I REVISÃO DE TEXTOS Fátima Áli | EDITORAÇÃO ELETRÔNICA Roka Estúdio

COMPÓS I www.compos.org.br

Associação Nacional dos Programas de Pós-Graduação em Comunicação

Presidente

Marco Roxo

Programa de Pós-Graduação em Comunicação - UFF

marcos-roxo@uol.com.br

Vice-Presidente

Isaltina Gomes

Programa de Pós-Graduação em Comunicação - UFPE

isaltina@gmail.com

Secretária-Geral

Gisela Castro

Programa de Pós-Graduação em Comunicação

e Práticas de Consumo - ESPM

castro.gisela@gmail.com

CONTATO I revistaecompos@gmail.com 